\title{
Creating Social Change: The Ultimate Goal of Education for Sustainability
}

\author{
Rashika Sharma and Sylila Monteiro
}

\begin{abstract}
Education is the vital link that brings about social change and generates synergies to address the interconnectedness between sustainability, society and the environment. Education empowers society to assume responsibility for sustainable living. This implies that educational processes and systems can transform perspectives and behaviour patterns, which in turn inculcates sustainable practices in all aspects of human life. Education is a precursor of change therefore educators are responsible for transforming communities and initiating social change. Developing and encouraging an awareness of sustainability in local communities further establishes patterns globally in communities' worldwide. Consequently 'glocal' synergies are created that ensure future graduates become citizens of the world with an ingrained consciousness of guardianship of the finite world. Contemporary education ought to embed core principles of sustainability which incorporates environmental, economic as well as social literacy into the curriculum. Through education, learners are creatively and critically stimulated into exploring the role of sustainable practice in all areas of human activity in society. This paper expounds the current sustainability strategy developed within a course at an institute of technology based in New Zealand. The course is designed to introduce the concepts and application of sustainability at entry level for a Bachelor's degree. In this paper an attempt is made to showcase the effectiveness of education in re-orienting student thinking to engage and instigate social change for our globalized world.
\end{abstract}

Index Terms-Education for sustainability, project based learning, social change, transformative learning.

\section{INTRODUCTION}

Social change leads to transformation in thinking which in turn influences behaviour patterns in society. Social change is an alteration in the thought processes of individuals that drives social progress. It may refer to a paradigmatic change in the socio-economic structure of today, characterised by complexity and global interdependence. Historically, social change has been driven by cultural, religious, economic, scientific or technological forces. Contemporary rapid technological advances and escalating global changes have impacted on the global economy in ways that are detrimental to the environment and communities, threatening the sustainability of our societies. To address the challenges faced by global communities, educational systems can transform values, attitudes and behaviour patterns to actuate social change. Education is a major instrument in initiating social

Manuscript received August 10, 2014; revised October 15, 2014.

The authors are with the Unitec Institute of Technology, Auckland, New Zealand (e-mail: rsharma@unitec.ac.nz,mchuo@unitec.ac.nz) adaptation "by bringing about a change in outlook and attitude of man. It can bring about a change in the pattern of social relationships and thereby it may cause social changes" [1]. Emerging new technologies test the existing social systems and often become an antecedent of more efficient human interconnectedness and globally accepted human communication.

Thus social change evolves progressively, sometimes dramatically as it has, in the last two decades. "Social change is a very complex and dynamic phenomenon that can be considered from a variety of perspectives and is reflected in a number of processes. These processes are different in different types of societies" [2]. Existing cultural, social and economic similarities and dissimilarities in various local environments affect these processes and shift societal structure globally, driving social change. Arab spring, Occupy protest are examples that illustrate how local is transmitted through social networking into the global field, influencing social thought processes and initiating change. Global technological advances are embraced in various environments and disseminated, localised and customised in the existing cultural, social and economic context. Localisation presents world readiness consequently glocal communities emerge with a commonality yet retaining aspects of the local identity. Global societies set common goals with local application thus globalisation becomes a worldwide phenomenon that drives social change. Education is a process which brings about behavioural changes in society, which enables every individual to effectively participate in the activities of society and to make positive contribution to the progress of society [3].

\section{TRANSFORMATIVE LEARNING: EDUCATION AND SOCIAL CHANGE}

Educational institutions can respond to social change in a variety of ways: they can alter their personnel practices, modify teaching methods to improve retention, devise new skills to change student attitudes towards social problems, create programmes and courses that assist in resolving difficulties resulting from altered social relationships [4]. Education is understood to be information transfer and knowledge acquisition. It is a transformative power that develops an initial awareness which then translates to inner sensitivity which facilitates significant personal change Transformational change of personal thoughts, attitudes, values and practices ultimately leads to social responsibility that broadens minds and creates a better society. A systemic change of educational culture towards the realisation of human potential and the interdependence of social, 
economic and ecological wellbeing can lead to transformative learning [5]. Sterling [5] recommended that educational methods that transform students' perspectives and viewpoints about sustainability will help create a sustainable future. Sterling's thoughts are similar to transformative learning theorised by Mezirow in 2000.

Mezirow's theory of transformative learning [6] states that teaching methods that allow learners to go through a process of critical reflection ensures a transformation or change in their thinking. Transformative learning occurs when individuals change their frames of reference by critically reflecting on their assumptions and beliefs and consciously making and implementing plans that bring about new ways of defining their worlds [7]. Transformative learning as experiencing a deep, structural shift in an individual's thoughts, feelings, and actions which results in a shift of consciousness that dramatically and irreversibly alters our way of being in the world [8]. Transformative learners can undergo change in their outlook on life and their interpersonal relationships, their connection with the natural environment and their ability to analyse alternative approaches to living. It involves more critical and forward thinking.

With transformative learning social change is inevitable. Curriculum can present opportunities for a shift in perspectives and mindsets of individuals in society. Lifestyle choices and thinking approaches alter communities, driving environmental, economic and social sustainability. Sustainability is therefore inherently about social transformation through formal and informal learning experiences.

\section{SYNERGIES}

In general, sustainability is understood as the capacity to support, maintain or endure. Sustainability is the ability to achieve economic prosperity while protecting the natural systems of the planet, and providing a higher quality of life for people. Sustainability is the integration of environmental, economic, and social dimensions of learning how to live differently, with an awareness of responsibility for global stewardship and management of global resources. Global sustainability therefore implies a sustainable future in which communities are: socially sustainable and care for each other with social justice and peace; environmentally sustainable protecting natural systems and use resources wisely; economically sustainable developing and satisfying valuable livelihoods for all; and governance interventions to implement appropriate policies to ensure the aforementioned three dimensions, the triple bottom line.

Consequently through education an awareness of this three-way relationship promotes 'glocal' synergies, a basis of an ingrained consciousness of guardianship of the finite world. In general, synergy originates from Greek meaning "cooperation" or "working together", is the combined working together of two or more parts of a system so that the combined effect is greater than the sum of the efforts of the parts [9].

Glocalisation implies the "meaningful integration of local and global forces" [10]. It refers to the adaptation of local conditions and the response of education locally, to the changing global environment. A three way synergy is established between an awareness of sustainability, local community development and global trends, held together with education. Education for sustainability is the instrument to facilitate 'glocal' synergies for sustainable living in the unpredictable future.

\section{TEAChing Practice In ACTION}

Curriculum design has significant impact on transformative learning to effect social change. Content, delivery and assessments need to challenge students to reflect and assimilate changing attitudes and thought processes that inculcate sustainable living.

The Bachelor of Applied Technology (BAT) programme at Unitec, New Zealand, offers specialisations in Automotive Technology, Marine Technology and Electrotechnology. The students in their first year of the BAT participate in the "Communication, Problem Solving and Health \& Safety" core course. The objective is to develop sustainability as a capability and this core course introduces them to sustainable practices, which progressively develops in complexity over the duration of the programme. During the second year of the programme students embark in another core compulsory paper entitled "Sustainable Technologies" which aims to allow students to explore various sustainable technologies within their own specializations. Finally, the third year core paper "Industry Project" presents them an opportunity to design technologies that can contribute towards sustainability. During this learning journey students undergo a general progression in their understanding of the complexity of sustainability. This paper describes this progression of learning and gradual cultivation of sustainable thinking that spans the total learner experience for the duration of the programme.

The purpose of this programme is to develop fundamental academic capabilities and soft skills that will be essential for their performance in industry. To encourage students to embrace the concept of sustainability and realize the relevance of sustainability within their specializations, the programme has sustainability integrated in various ways in the curriculum. The principal objective is in building competencies for sustainability. The assessments within the programme range from individual assessments to collaborative group projects where students design and develop creative solutions to existing environmental issues within their particular technical specializations. Fig. 1 shows a typical example of the assessment given to the students in year 1 of the BAT.

This assessment presented in Fig. 1 introduced at the outset presented a completely different learning approach for the students. Their critical thinking was challenged, the realization that ownership of their learning was their responsibility. The collaborative feature of the project replicated real world learning and exposed them to the environmental problems related to their specific disciplines. All students in the first year on the Bachelor of Applied Technology programme completed this project before progressing to the second year of study. With the foundations for sustainability laid out in this year 1 course, 
the later courses then give students an opportunity to further build on sustainability skills. After the completion of the 3 year programme it is envisaged that the graduate will enter the real world with sustainability embedded in their worldview.

\section{Methodology}

Research was conducted to obtain student feedback on their understanding of sustainable practices and to gauge if the BAT programme was successfully creating sustainable practitioners for the real world. A semi-structured questionnaire was administered to 60 students from the Bachelors programme in 2013. 20 students from each degree level voluntarily participated in the research and generated a $100 \%$ response rate. This ensured that the feedback generated encompassed the entire BAT programme. Quantitative questions produced statistical data that was used for comparison purposes and qualitative questions yielded a good spectrum of student opinions and perceptions on the concept of sustainability. This research paper focuses on one of the key questions in the survey where students were simply asked to define the concept of sustainability. The transition in student's definition of sustainability was instantly obvious.

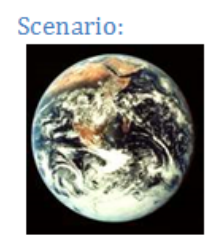

Our Finite World

Limited space

Limited resources

Growing population

Project:

What is ONE of the BIGGEST PROBLEMS facing your INDUSTRY today?

Investigate this problem and develop a creative solution in your project teams. You will presentyour idea to the 'Our Finite World' panel to try and secure funding for your proposed solution. In order to achieve funding your product or service must meet the following criteria:

Your product or service must be:

1. NEW / UNIQUE - It does not exist at the moment.

2. CREATIVE / INNOVATIVE - It may use existing technology or systems in DIFFERENT ways. It can be a new application of an existing idea. It is imaginative, exciting, ground-breaking, thoughtful.

3. ECO-FRIENDLY - It is environmentally friendly.

4. NZ-SPECIFIC - It is developed within the laws and regulations specified in NZ.

Fig. 1. Eco-friendly product design scenario given to year 1 students.

\section{TRANSFORMATION}

The understanding of the concept of sustainability became more comprehensive and complex with students progression through the degree programme changing in essence from year 1 to year 3 (refer to Fig. 2). Student's definition of sustainability appeared simple and focused on environmental dimensions in their first year, becoming more complex and holistic as they progressed to the third year. The third year students had a greater degree of exposure to sustainability concepts hence their definitions focused on a combination of environmental, social, and economic attributes.

The comments presented in Fig. 2, rightly confirms Sterling's [5] suggestion that educational methods can transform students' perspectives and viewpoints about sustainability. Sustainability awareness is thus ingrained in the student psyche and holds the key to social change, promising future environmental well-being. A third year degree student comment that 'The first sustainability paper (Communication, Problem Solving and Health \& Safety) I took sparked a real urgency' is a reflection of the kind of change awareness can create. Therefore evidently educational methods and a curriculum that allows students to work on collaborative environmental projects, designed to encourage lateral and critical thinking is the pathway for sustainability education.

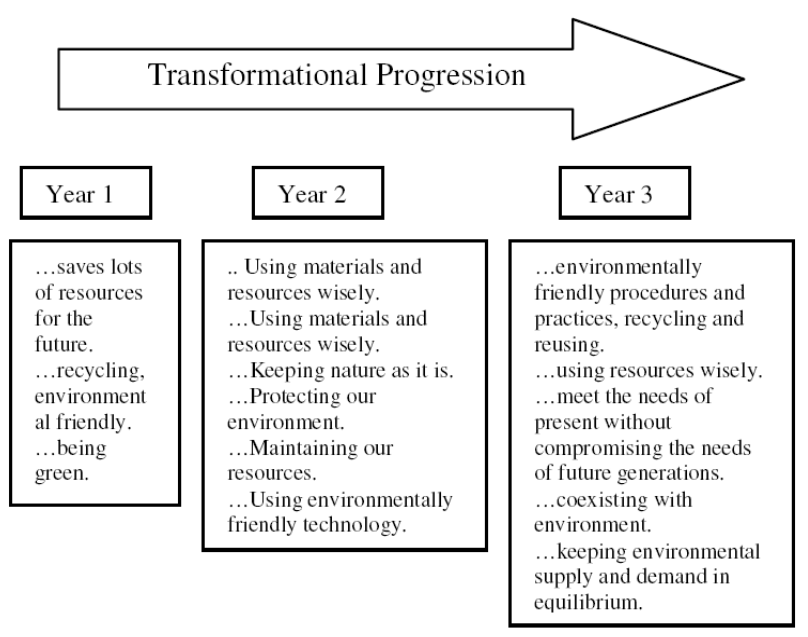

Fig. 2. Transformation in student's perspectives of 'sustainability' through the programme.

\section{Designing Projects That TRANSForm}

The three years progression develops the ecological, economic, social and political dimensions of the concept of sustainability. The programme focusses on the social change objective of the idea of sustainable development, including the need for social learning and for capacity building. The curriculum design is a combination of project and problem based "situated learning" that stimulates the transformative learning process. "In project teaching, students follow their own "path of learning" and in this way they learn to distinguish which knowledge is required in order to find solutions to the problem" [11]. Through this group project design, students interpret and analyse environmental problems at both micro and macro levels thus preparing them for the glocal perspectives. Students are able to accumulate their existing repository of knowledge within a new context which can have global application. Thus human behavioural patterns in relation to environmental sustainability lead to social change. Consequently 'glocal' 
synergies are created that ensure future graduates become citizens of the world with an ingrained consciousness of guardianship of the finite world.

It is interesting to see how problem based projects are currently incorporated in the sustainability education curriculum in educational institutions worldwide. Lecturers from Manchester Business School, University of Manchester, Manchester, UK, cite examples of how this approach has been successfully implemented using interdisciplinary, problem-based delivery. For the design of the project the problem scenarios are negotiated between students and facilitator and appropriate to the local or global context. Few of the project examples are listed below [12]:

- Wheels: Appropriateness of Corporate Social Responsibility (CSR) tools in a tyre manufacturing organization, barriers to organisational change, CSR models and techniques, greenwash, strategy, stakeholder engagement

- Shelter: International crisis response - developing transitional housing strategy, cultural impacts, international co-operation, appropriate technology, resilience, stakeholder engagement

- Energy: Evaluating energy micro generation for new build housing, multi-dimensional cost benefit analysis, public engagement, social, economic and technical constraints, influencing behavior.

- Plastic: Public consultation for siting a PVC recycling facility, stakeholder and public engagement, life-cycle analysis, land use planning, social, economic and environmental aspects.

Five criteria for the project design as complexity, currency, content, context and cumulative [12]. Complexity focusses on a non-reductionist approach; currency meaning topical, unsolved projects; content that leads to transformational behaviour; context specific to the profession and discipline; finally cumulative presenting an on-going and coherent learning experience [12]. These aforementioned citations validate the transformational progression that ensues in the Bachelor of Applied Technology programme at Unitec, New Zealand, through the core generic courses for the three technical specialisations (Automotive Technology, Marine Technology and Electrotechnology) over the three year duration.

\section{GLOCAL CONTEXT}

The problem solving process within the projects is founded not on economic viability and profit but on those aspects of life that can provide meaningful social and environmental interconnectedness for society. Sustainability education leads to social responsibility almost by osmosis a conscious and unconscious awareness that pervades the assimilation of knowledge and stimulates behavioural change. The localisation of sustainability education simply implies contextualising the project scenarios to acknowledge and appreciate the geographical, pedagogical, technical or cultural diversity of the local society. The process of contextualisation leaves room for adaptability in global settings facilitated by social media and networks and information technology. Transferrable skills and capabilities develop that enable learners to adapt to other contexts in the unpredictable future. Technology brings the world closer and is a forum for global exchanges. Technology is a tool that furthers education for social change and to give the learners, digital natives of today a local setting with global implications and global contexts. Consequently 'glocal' synergies are created that ensure future graduates become citizens of the world with an ingrained consciousness of sustainability and social responsibility.

\section{CONCLUSION}

It is indisputable that desirable and enduring social change can be addressed through sustainability education. The approaches, delivery and tools used for teaching and learning need to be current and reflect technological changes that take place to ensure maximum student engagement. Yet the overarching objective of a programme should aim for a holistic approach to broaden minds and develop student thinking, at all levels, in the creation of a better society. Social and ecological sensitivities through sustainability education inculcate social responsibility which in turn drives social change. In Dewey's essay, "Education and Social Change," one can observe traces of progressivism as he supports the notion that society is constantly changing, and that education reflects, generates, and guides social change. Dewey argues that education has the power to lead society down certain paths. The interconnectedness between sustainability, society and the environment permeates through education into the local communities. Social responsibility extends to technologically driven glocal synergies promoting global social change.

\section{REFERENCES}

[1] Sociology Guide. Education and Social Change. [Online]. Available: http://www.sociologyguide.com/education/education-and-socialchange.php

[2] M. Pavlova, "Social Change: how should technology education respond?" International Journal of Technology and Design Education, vol. 15, no. 3, pp. 199-215, 2005.

[3] H. Yadav. Education Brings about Social Change. [Online]. Available: http://www.social-media.ezinemark.com/education-brings-aboutsocial-change-7d337b4c67a9.html

[4] C. Lieberman, "Education and social change," American Secondary Education, vol. 7, no. 3, pp. 42-48, 1977.

[5] S. Sterling, Sustainable Education: Re-Visioning Learning and Change, Green Books Ltd, UK, 2001.

[6] J. Mezirow, "Learning to think like an adult: core concepts of transformation theory," Learning as Transformation, San Francisco: pp. 3-34, 2000.

[7] K. Dover. (2005). Theory of Tranformative Learning. [Online]. Available: http://www.adulted.about.com/cs/learningtheory/a/mezirow_p.htm

[8] E. O'Sullivan, Transformative Learning: Educational Vision for the $21^{\text {st }}$ Century, OISE/UT/ZED Books, London, 1999.

[9] M. Rouse. (2006). What is Synergy. [Online]. Available:http://www. whatis.techtarget.com/definition/synergy

[10] J. Brooks and A. Normore, "Educational leadership and globalization literacy for a glocal perspective," Educational Policy, vol. 24, no. 1, pp. 52-82, 2010.

[11] P. Leroy, H. Bosch, and S. Lighart, "The role of project-based learning in the political and social sciences of the environment curriculum at Nijmegen University," International Journal of Sustainability in Higher Education, vol. 2, no. 1, pp. 8-20, 2001.

[12] H. E. Dobson and C. B. Tomkinson, "Creating sustainable development change agents through problem-based learning: 
Designing appropriate student PBL projects," International Journal of Sustainability in Higher Education, vol. 13, mo. 3, pp. 263-278, 2012.

[13] J. Dewey, Education and Social Change, McGraw-Hill Dushkin, pp. $333-341,2001$

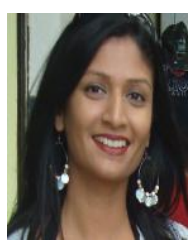

Rashika Sharma is a lecturer in integrated practice at Unitec Institute of Technology in New Zealand. She is specialized in sustainable practice, societal context and generic skills in the bachelor of applied technology.

She is currently pursuing a doctoral degree in education from Deakin University in Australia.

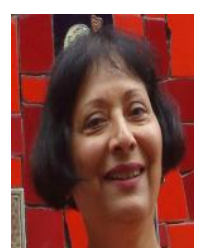

Sylila Monteiro is a lecturer/curriculum leader in the Department of Communication Studies. She teaches the bachelor of communication and the bachelor of applied technology. She previously taught at Zambia Institute of Technology in Zambia now The Copperbelt University in Kitwe, Zambia. 